\title{
Constructivism and the Problem of Normative Indeterminacy
}

\author{
[Penultimate draft; final and authoritative version forthcoming in The Journal of $V$ alue Inquiry]
}

Abstract. I describe a new problem for metaethical constructivism. The problem arises when agents make conflicting judgments, so that the constructivist is implausibly committed to denying they have any reason for any of the available options. The problem is illustrated primarily with reference to Sharon Street's version of constructivism. Several possible solutions to the problem are explained and rejected.

Metaethical constructivism is a view that purports to explain the nature of practical (and in some versions, also epistemic) normativity in a distinctive way. It aims to vindicate the existence of normative facts or truths by revealing the nature of those facts or truths as not wholly independent of what we take them to be. The view (unpacked in a bit more detail below) carries considerable appeal. It eschews any problematic commitments to a rich metaphysics of mind-independent normative facts; it is compatible with naturalism, invoking familiar psychological notions such as judgment and attitude; and it can readily explain how awareness of normative facts or truths carries motivational force, given their grounding in the agent's own judgments. However, despite such theoretical advantages, constructivism has also been subject to extensive critical scrutiny, questioning its very coherence and its status as a distinctive metaethical position, among other things. ${ }^{1}$

This article draws out a problem for metaethical constructivism which has so far gone unnoticed in the debate. It is a familiar complaint that constructivism allows for both too many, and too few, reasons. For example, if an ideally coherent Caligula judges he has reason to torture people for fun, then constructivism seems to imply he has reason to do so. ${ }^{2}$ And conversely, it is unclear that one would have any reason to e.g. save a child from drowning at no cost to oneself if one does not judge there is such reason. However, what is not familiar is that constructivism also suffers from a complementary problem of normative indeterminacy, where agents implausibly lack reasons to perform any action in a given scenario due to their incoherent judgments. For concreteness (and brevity), this problem will be illustrated on Sharon

\footnotetext{
${ }^{1}$ For discussion, see e.g. David Enoch, "Can there be a Global, Interesting, Coherent Constructivism about Practical Reason?”, Philosophical Explorations 12 (2009): 319-339, and Karl Schafer, "Realism and Constructivism in Kantian Metaethics", Philosophy Compass 10 (2015): 690-701.

2 See Allan Gibbard, "Morality as Consistency in Living: Korsgaard's Kantian Lectures”, Ethics 110 (1999): 140-164, among several others. The labels 'too few reasons' and 'too many reasons' are borrowed from Mark Schroeder, Slaves of the Passions (Oxford University Press, 2007), chs. 5-6, although Schroeder discusses very different problems.
} 
Street's version of constructivism - easily one of the best-developed versions in the literature. The problem does seem to generalize so as to impugn also other versions of the view, such as e.g. Korsgaard's. ${ }^{3}$ The (otherwise significant) differences between Korsgaard's Kantian position and Street's Humean position do not seem to matter here. But this point will not be defended at any length this article. $^{4}$

A central component of the constructivist metaethics is what Street herself dubs the 'practical point of view', viz. 'the point of view occupied by any creature who takes at least some things in the world to be good or bad, better or worse, required or optional, worthy or worthless, and so on - the standpoint of a being who judges ... that some things call for, demand, or provide reasons for others'. ${ }^{5}$ The constructivist's explanatory strategy starts off by providing what Street calls a 'formal characterization' of the practical point of view. The characterization is meant to be formal in making no reference to specific normative content, and presupposing no particular normative judgment. It merely describes, in normative-free terms, what is constitutively involved in making normative judgments: what mental economy an agent must minimally possess for her to occupy the practical standpoint. Once this thin, normative-free notion of a practical standpoint is in place, the constructivist goes on to claim that all normative facts consist in what is entailed from within this standpoint; there are no normative facts that outstrip the content of judgments made from the practical point of view.

In this way, a normative judgment - for example, a judgment that one ought to $V$ - is thought to give rise or 'construct' the normative fact that one ought to $V$. But what does it take for a judgment to be made? The answer, as constructivists are quick to point out, cannot be restricted to one's explicitly judging that one ought to $V$, e.g. by sincerely uttering words to that effect. For such a restriction to explicit judgments would commit the constructivist to highly counterintuitive results. To see this, consider an example adapted from one of Street's own ${ }^{6}$ in which an agent judges that she has conclusive reason to get to Rome immediately but does not recognize that taking a plane is a necessary means of doing so. Now it

\footnotetext{
${ }^{3}$ For Korsgaard's view, see Christine Korsgaard, The Sources of Normativity (Cambridge University Press, 1996); Christine Korsgaard, Self-Constitution (Oxford University Press, 2009).

${ }^{4}$ The main difference between Street's view and Korsgaard's consists in the fact that, whereas for Street it is normative judgments that construct reasons, for Korsgaard it is acts of 'willing' (cf. Street 2008: 228 n. 38). And since Korsgaard's willing, just like Street's judgment, is subject to certain constitutive standards of coherence and consistency, a very close version of the problem described here will arise equally for Korsgaard's view, as should become clear later.

${ }^{5}$ Sharon Street, "What is Constructivism in Ethics and Metaethics?", Philosophy Compass 5 (2010): 363-384, p. 366.

6 Sharon Street, "Constructivism about Reasons", Oxford Studies in Metaethics 3 (2008): 207-245, p. 227.
} 
would be highly counterintuitive to allow that the agent has no reason to take a plane just because she fails to recognize the instrumental relation this action bears to the object of her explicit judgment. Street's view blocks this problematic implication:

[1] $f$ one genuinely judges oneself to have conclusive reason to $Y$, and it is a fact (of which one is not aware) that $Z$ is a necessary means to $Y$, then by one's own lights as someone who genuinely judges herself to have conclusive reason to $\mathrm{Y}$, one has a reason to $Z$, even though one is not currently aware of this. In other words, simply by judging yourself to have reason to $Y$, you're thereby-as a constitutive matter-also judging yourself to have reason to take the means to $Y$, whatever those may be. ${ }^{7}$

Failing to notice that $Z$-ing is necessary to $Y$-ing does not imply that one has no reason to $Z$, since one has in fact implicitly judged that one has reason to $Z$. Similar points are meant to handle oversights of logical consistency, as well as conflicts between judgments. ${ }^{8}$ Thus, since genuine judgments constitutively exhibit logical and instrumental coherence, a set of logically or instrumentally conflicting 'judgments' are in fact no judgments at all. For example, if one 'judges' that one ought to $Y$, and at the same time (and in full conscious awareness) also 'judges' that one has no reason to take the recognizably necessary means of $Z$-ing, then according to Street, one has not in fact made either judgment, and no normative fact about one's reasons in this case has been constructed. ${ }^{9}$

However, this treatment of conflicting judgments allows the threat of extensive normative indeterminacy to emerge. Consider, to see the problem this paper is concerned with, a scenario in which you judge you ought to have something for lunch. At the local café, you are presented with two options, a soup and a salad. But suppose you suffer from choice-crippling incoherence: you judge you ought to choose the soup over the salad, and also that you ought to choose the salad over the soup (you are aware you cannot have both). Your judgments are in direct conflict. To clarify: You are not 'indecisive' in the sense of trying on both judgments for size without (yet) endorsing either. Rather, you judge both that you ought (all things considered) to have the salad, and that you ought (all things considered) to have the soup.

\footnotetext{
${ }^{7}$ Street, "Constructivism about Reasons", op. cit., p. 229. Emphases in the original. Street gives a parallel verdict about agent who do recognize that $Z$-ing is necessary to $Y$-ing.

${ }^{8}$ Street, "Constructivism about Reasons", op. cit., and Sharon Street, "In Defense of Future Tuesday Indifference: Ideally Coherent Eccentrics and the Contingency of What Matters", Philosophical Issues 19 (2009): 273-298, p. 274. ${ }^{9}$ Street, "Constructivism about Reasons", op. cit., p. 228. In the passage quoted above, Street frames her view in terms of judgments concerning what the agent has conclusive reason to do rather than what she ought to do. However, here and throughout, I am using 'ought' as equivalent to 'has conclusive reason'. I have opted for the former purely to save words.
} 
Considerations of interpretive charity may incline us to interpret you as being indecisive. But we are assuming here that charity fails. You are in a deeply incoherent state. In fact, it may well be correct to insist, as the constructivist would, that you are conceptually confused and have actually failed to make either judgment. The question for us is how, if at all, your confusion affects the normative landscape.

According to the constructivist, your confusion prevents both 'judgments' from counting as genuine judgments, and so prevents them from constructing the reasons they would otherwise construct. But to deny that such cases involve any reasons one way or the other is to embrace an odd kind of normative indeterminacy. ${ }^{10}$ On a natural understanding of the case, both your judgments are mistaken: you have only some reason to have the soup and only some reason to have the salad since both options are, we may suppose, (roughly equally) nice, nutritious, filling, inexpensive, and so on. But on the constructivist view, these features of the soup and the salad do not provide you with reasons to choose either unless you judge you have such reasons. And the case is such that the only 'judgments' you have made (at least explicitly; more on this below) are the original conflicting pair: that you ought to choose the soup, and that you ought to choose the salad. Since the conflict prevents both from counting as genuine judgments, you would seem to have no reason one way or the other. And that is highly implausible.

Some such apparent conflicts between judgments are in fact resolved, according to Street, by their order of priority. To illustrate this, one example she gives is that of an agent who judges she has conclusive reason to eat a bowl of chili, and also judges she has conclusive reason to lead a long and healthy life. Now if the bowl of chili contains nuts, which the agent is allergic too, her judgments will conflict. But no indeterminacy results, according to Street, since (assuming the agent is remotely statistically normal) her judgment that she has conclusive reason to lead a long and healthy life is much more deeply held or much more deeply 'hers', in the sense that it supports and is supported by a great number of other things she takes herself to have reasons to do. Thus, it is the judgment that she ought to live a long and healthy life, which in turn implies she ought not eat the chili, which resolves the conflict and constructs the normative fact in this scenario. ${ }^{11}$ But, however successfully this handles conflicts of the sort imagined by Street, it is no help with the present one. For the present case is such that both

\footnotetext{
${ }^{10}$ How common are cases of this sort? I return to this question later. As I explain there, even if these cases are merely possible, they should not for this reason be dismissed out of hand, even by Street's own lights. I am grateful to an anonymous referee for raising this issue.

11 Street, "Constructivism about Reasons", op. cit., p. 235.
} 
judgments are roughly equally, and fairly weakly, held. Both pertain to everyday humdrum choices, and so neither bears on or reflects your deeper convictions, values, or projects.

Of course, as described, the case only cites your explicit judgments. And we have seen that constructivists standardly appeal to implicit judgments precisely in order to resolve apparent normative conflicts on the explicit level. Is there an implicit judgment you plausibly made which could resolve your conflict? We have seen above how Street emphasizes that certain judgments are constitutively implied by other judgments. For example, judging that one ought to $V$ implies judging that one ought to take the necessary means to $V$-ing, even if one is not aware they are necessary, and even if one judges there is no reason to take them. Similarly, it may be urged, each judgment about the lunch option you ought to have implies a corresponding judgment that you have some reason for each option. That would eliminate any normative indeterminacy.

However, even if we accept that a judgment that one has some reason to $V$ is implied, as a constitutive matter, by a judgment that one ought to $V$, still this cannot construct reasons for you to have the soup or the salad and eliminate the indeterminacy. This is because further judgments can only be implied by genuine judgments, not bogus or pseudo-judgments. Only if one genuinely judges that one ought to have the soup (salad), could it conceivably be the case that one thereby also implicitly judges that one has some reason to have the soup (salad). And the - direct, clear-eyed - conflict between your two judgments reveals, according to the constructivist, that in fact you have not managed to make any genuine judgments in the first place. You are not doing what is constitutively involved in judgment making - and this extends to any implicit judgments.

At this point, a natural reply suggests itself. While your pair of conflicting 'judgments' are jointly incoherent and hence bogus judgments, there is a different judgment you made further upstream, viz. the judgment that you ought to have something for lunch. And this (perfectly coherent) antecedent judgment may in turn imply, as part of what constitutes judgment-making, further coherent judgments about the particular options you are presented with. Specifically, the antecedent judgment may constitutively imply the judgment that you have some reason to have the soup, and some reason to have the salad. Normative indeterminacy would be avoided. Moreover, the implied judgments that you have some reason for each option would construct precisely the reasons you are intuitively understood as having. 
The reply squares badly with the constructivist's view, however. It requires modifying or augmenting the original transmission principle of reasons from ends to means that Street officially endorses. And the augmented transmission principle does not merely change the letter of constructivism; it runs counter to its spirit. As the passage quoted above confirms, Street endorses:

Judgment Necessity] If one judges that one ought to $E$, and $M$-ing is a necessary means to $E$-ing, then one judges that one has a reason to $E$.

Since judgments construct reasons, this implies the following transmission principle:

[Ought Necessity] If one ought to $E$, and $M$-ing is a necessary means to $E$-ing, then one has a reason to $M$.

Street plainly cannot invoke Ought Necessity to derive a reason to have the soup (salad). ${ }^{12}$ Even if one judges that one ought to have something for lunch, still having the soup (salad) is not a necessary means to one's end. But it is a sufficient means. And the present suggestion is that Street might instead rely on a corresponding transmission principle for sufficient means. Perhaps, the thought goes, the following principle holds:

[Judgment Sufficiency] If one judges that one ought to $E$, and $M$-ing is a sufficient means to $E$-ing, then one judges that one has a reason to $M$.

This would imply the following transmission principle for reasons:

[Ought Sufficiency] If one ought to $E$, and $M$-ing is a sufficient means to $E$-ing, then one has a reason to $M$.

Ought Sufficiency is a highly contentious principle. One hotly debated problem it faces is that some means are objectionable or problematic, and it then seems we have no reason to take them. Suppose, to

${ }^{12}$ Street could, however, invoke Ought Necessity to derive a reason to (have the soup or the salad); more on this below. 
rehearse a famous example, that one ought to alleviate one's pangs of hunger. One sufficient means to achieving this is eating a tasty lunch; another is killing oneself. But one seems to have no reason to kill oneself. ${ }^{13}$ A common reply to this problem invokes pragmatic considerations to explain away the apparent falsity of claiming that one has a reason to kill oneself. This claim only sounds false, the reply goes, because it cites a very weak reason, massively outweighed by countervailing reasons. But claiming that one has reason to $V$ generates an expectation that the reason cited is in fact weighty: what would be the conversational point of claiming that one has a massively outweighed reason to $V$ ? $^{14}$

This is not the place to determine whether the pragmatic reply successfully salvages Ought Sufficiency. But even if it does, this would not help the constructivist. For even if the reply is successful, still Ought Sufficiency remains particularly ill-suited to constructivism. To see this, go back to the example above. If Ought Sufficiency is true, the agent who ought to alleviate her hunger has a (possibly very weak) reason to kill herself. According to the line of thought we are presently considering, this reason would be constructed, in line with Judgement Sufficiency, by her corresponding implicit judgment that the agent has a reason to kill herself. However, agents often independently judge they have no reason to kill themselves. Assuming the agent enjoys a rich and satisfying life with plenty to look forward to, and is not clinically depressed etc., she will judge there is no reason for her to kill herself. Moreover, this judgment may well turn out to be one of those deeply held judgments to which Street assigns normative priority over more shallow judgments.

As we have seen, Street emphasizes that a judgment that one ought not to kill oneself is typically deeply held and can hence trump a conflicting, more shallow judgement (e.g. that one has reason to eat some allergy-inducing food). Now a judgment that one has no reason to kill oneself could be just as deeply held, and hence plausibly enjoys the same normative priority. But endorsing Judgment Sufficiency would force Street to abolish its priority. It would force her to concede that the judgment that one has no reason to kill oneself is in fact trumped by the implicit judgment that one has a reason to do so; the latter judgment manages to construct a reason, via Ought Sufficiency, in the face of the former contrary judgment. This concession would be particularly awkward for Street given that, as the pragmatic defence

\footnotetext{
${ }^{13}$ John Broome, "Have We Reason to Do as Rationality Requires? — A Comment on Raz," Journal of Ethics and Social Philosophy, Symposium 1 (2005): 1-8.

${ }^{14}$ See Schroeder, Slaves of the Passions, op. cit., and Joseph Raz, "Instrumental Rationality: A Reprise," Journal of Ethics and Social Philosophy, Symposium 1 (2005): 1-19.
} 
of Ought Sufficiency suggests, the reason to kill oneself is a very weak one. Thus a very weak reason would nevertheless somehow manage to trump the normative fact constructed by a deeply held judgment.

In response, the constructivist may attempt to reapply the pragmatic line of defense. Perhaps one's judgment that one has no reason to kill oneself rings true because, once again, we are naturally prone to interpret it in terms of weighty reasons. But the reason one has to kill oneself is intended to be very slight. Hence it may still be that one hasn't in fact judged that one has no reason to kill oneself, but only that one has no weighty reason to do so.

The suggestion may seem initially promising, but it ultimately fails. At best, the pragmatic defense may explain why an (uttered) judgment that sounds true is in fact false (or vice versa). But in doing so, it obviously cannot override the agent's own intended meaning in making the judgment. If the agent herself states that she has no reason to $V$ but there are nevertheless grounds for supposing that she only has weighty reasons in mind when making this statement, then the constructivist may be able to invoke the pragmatic defense to explain away the apparent discrepancy. But there are agents for whom no such grounds will exist. For instance, if the agent in the above example is John Broome, we seem to have no grounds to suppose that he has only weighty reasons in mind when judging he has no reason to kill himself to alleviate his pangs of hunger. For Broome explicitly rejects Ought Sufficiency, and we may stipulate that he has made no other judgment that implies he has any such reason. Thus when Broome judges he has no reason to kill himself, his judgment should be taken at face value. And therefore, the awkward conflict with the slight reason supposedly implied by Ought Sufficiently still stands. ${ }^{15}$

For these reasons, Ought Sufficiency is an uncomfortable bedfellow of constructivism, and hence cannot plausibly be invoked to eliminate the indeterminacy you face and derive a reason for you to have the soup, or a reason for you to have the salad. For Ought Sufficiency licenses the construction of reasons to take problematic or objectionable means to one's ends. And even if the reasons so constructed are very slight, as the standard pragmatic defence of Ought Sufficiency maintains, the constructivist would face the awkward implication that very slight reasons can nevertheless somehow trump the weighty reasons provided by one’s deeply held judgments.

\footnotetext{
15 The point in the text does not depend on the agent in question being sufficiently sophisticated and opinionated to reject Ought Sufficiency, as John Broome is. Any agent who does not subscribe to Ought Sufficiency, for whatever reason, and for whom there is no other cause to attribute to her a judgment that she has some reason to kill herself, will serve equally to illustrate the failure of the pragmatic defense.
} 
Perhaps, however, the constructivist could avoid the problem in a different way. That is, perhaps she could deploy the following modified version of Ought Sufficiency:

[Ought Sufficiency*] If one ought to $E$, and $M$-ing is a sufficient means to $E$-ing, then one has a reason to $M$, unless one judges that one bas no reason to $M$.

The additional clause in Ought Sufficiency* blocks reasons to take problematic means from defeating (weightier) reasons given by one's normative judgment. And importantly, it seems to achieve this in a constructivist-friendly way, respecting as it does the normative authority of one's own countervailing judgment. ${ }^{16}$ However, this proposed solution sets up an internal clash between one's judgments that would commit the constructivist, counterintuitively, to denying that one really ought to $E$ as one originally judged. To see this, consider first what Street herself has to say about a parallel clash where one's judgment concerns necessary, not sufficient, means:

$[S]$ omeone who "judges" that she has conclusive reason to $Y$, but who (at the same time, in full consciousness) "judges" that she has no reason whatsoever to take what she recognizes to be the necessary means to $Y$, is not making a normative judgment. ${ }^{17}$

As the quote illustrates, if a parallel clause to the one being presently considered were added to Ought Necessity, it would oddly license the undercutting of the original judgment that one has conclusive reason to $Y$. For example, the agent who judges she has conclusive reason to get to Rome immediately but fails to recognize that taking a plane is a necessary means for doing so, would actually have no reason to get to Rome immediately if she also (reasonably enough from her point of view) judges she has no reason to get on a plane. This result runs counter to the very purpose of according normative priority to constitutive relations among judgments over the content of those judgments. The purpose of this move, recall, is inter alia to block factual and conceptual errors from too easily preventing the construction of reasons by judgments. But this is precisely what would happen in e.g. cases such as the would-be Rome traveler, according to Street herself, if Ought Necessity were modified in the way proposed.

\footnotetext{
${ }^{16} \mathrm{I}$ 'm indebted to an anonymous referee for getting me to consider this response to the problem.

${ }^{17}$ Street, "Constructivism about Reasons", op. cit., pp. 227-228.
} 
Now of course it is Ought Sufficiency rather than Ought Necessity for which the modification is proposed. However, there does not seem to be any principled reason to treat Ought Sufficiency differently from Ought Necessity. If a countervailing judgment can defeat reasons provided by the constitutive relations that obtain between judgments, as Ought Sufficiency* has it, then it seems this should hold uniformly across the full range of normative principles the constructivist endorses. Otherwise, it would not amount to a principled feature of the constructivist view but rather an ad hoc solution to the present problem. Therefore, if parity of treatment is maintained, Ought Sufficiency* should be taken to imply that, for example, the agent who 'judges' she ought to alleviate her pangs of hunger but also 'judges' she has no reason to kill herself, actually does not ought to alleviate her pangs of hunger at all since in fact she makes no judgment to that effect. The proposed solution thus yields a strange result that cuts against the constructivist's view.

It might be thought, however, that there is actually no need for Street to opt for either Ought Sufficiency or Ought Sufficiency*. Perhaps a reason for you to have the soup and a reason for you to have the salad both follow from Judgment Necessity, in the following way. Your judgment that you ought to have something for lunch must conform to Judgment Necessity. Since [having the soup or the salad] is a necessary means to having something for lunch, you have judged that you ought to [have the soup or the salad]. And perhaps a judgment that you ought to [have the soup or the salad] implies, as a constitutive matter, a judgment that you have some reason to have the soup and some reason to have the salad, as specified by the following principle:

Judgment Disjunction] If one judges that one ought to [E or $F]$, then one judges that one has some reason to $E(F)$.

Judgment Disjunction would ensure that you have some reason to have the soup and some reason to have the salad, via the following transmission principle:

[Ought Disjunction] If one ought to $[E$ or $F]$, then one has a reason to $E(F)$.

One way of understanding the present proposal reintroduces Ought Sufficiency and its problems. Since E-ing (F-ing) is a sufficient means to [E-ing or F-ing], Judgment Disjunction can be seen as a 
corollary of Judgment Sufficiency, and Ought Disjunction as a corollary of Ought Sufficiency. But the constructivist could propose Judgment Disjunction as an independent constitutive principle of judgmentmaking, without also relying on the problematic Judgment Sufficiency. However, doing so would not prevent a very similar problem from recurring. To see this, suppose you judge you ought to thave something for lunch or kill yourself] so as to be finally rid of your hunger. There need be no reason for you to kill yourself, by the constructivist's own lights, if you have not judged you have reason to kill yourself. And invoking pragmatic considerations to insist that you do have a (very slight) reason to kill yourself will face a parallel problem to the one raised above for Ought Sufficiency. Judgment Disjunction therefore fares no better than Judgement Sufficiency in tackling the constructivist's problem of normative indeterminacy.

The problem, which this paper has been at pains to draw out, can be traced back to a fundamental insight that the constructivist herself is (rightly) keen to respect. Street identifies the source of reasons with our normative judgments. But the activities of reasoning and judgment-making are notoriously susceptible to factual and conceptual confusion, whereas normative reasons are more robust. To get around this mismatch, Street relies on a set of principles that override the authority of factually or conceptually confused judgments. But the problem is that this strategy only manages to screen off some confusions.

In the central example used to illustrate the problem, while going over your options for lunch, you judge that you ought to order the soup, and you judge that you ought to order the salad. The conflict implies that neither option is one you in fact ought to order. Moreover, while you may recognize, as the example allows, that both options are nice, nutritious, filling, and so on, you do not take these features to be reasons for choosing either option. This suggests that no such feature should in fact count as a reason for so choosing. According to Street, then, your confusion leaves you with no reasons one way or the other. Several possible ways for Street to avoid this counterintuitive implication have been unfavourably examined. It seems that no plausible normative principle manages to screen off your confusion. Could the constructivist instead accept this result, while offering considerations that mitigate its counterintuitiveness? For example, focusing on your own recognition that both lunch options are nice, 
nutritious, etc., the constructivist may suggest that if you nevertheless fail to regard these features as reasons for choosing each option, then it is not so odd to accept that you may indeed have no such reasons. ${ }^{18}$

Street herself opts for a broadly similar strategy when dealing with a different type of counterintuitive implication of her view, mentioned in passing above. Intuitively, certain 'ideally coherent eccentrics' (ICEs) as Street dubs them, seem to be making a normative mistake. ${ }^{19}$ For example, an ideally coherent Caligula may judge that he has reason to inflict suffering on others, but intuitively he is mistaken. And an ideally coherent anorexic may judge that she has reason to starve herself to death, but intuitively she is mistaken. Now Street's view denies the appearance of (normative) error here. Her way of handling ICEs invites us instead to take a closer look at what being such a character actually involves. Doing so should, she suggests, significantly (perhaps entirely) mitigate the counterintuitiveness of accepting the ICE's judgments as true. For example, if the ideally coherent anorexic values starving herself to death for the sake of having a trim figure over anything else; and if this preference of hers is fully consistent with all the relevant non-normative facts; and if moreover she has no 'deeper normative commitments according to which this is a stupid and unworthy value' - then, Street claims, the case no longer seems so odd:

"Go for it," we might say to her, after long talks with her in which we assured ourselves of her flawless consistency and lack of illusions about the non-normative facts. "I guess you should do whatever floats your boat, if you really feel that strongly about it." ${ }^{20}$

However successful this strategy is in dealing with the threat of ICEs, however, a similar line does not seem promising in the present case. A full development and examination of this strategy goes beyond the scope of the present paper, but the following remarks explain the initial verdict. Looking more closely at your situation when you make the conflicting judgments about your lunch options may reveal just how deeply incoherent and confused you must be. It might also reveal that your case is not very common, as it differs from ordinary cases of dithering and indecision, for example. ${ }^{21}$ But none of this bears on the

\footnotetext{
${ }^{18}$ I'm grateful to an anonymous reviewer for highlighting this response to the case.

${ }^{19}$ See Street, "In Defense", op. cit.

${ }^{20} \mathrm{Ibid}$, p. 280.

${ }^{21}$ It might be thought that a closer examination of your case is likely to reveal that it is purely hypothetical and not one that is ever likely to materialize in real life. But even that, as Street acknowledges with respect to ICEs, would not prevent the case from counting as a counterexample, for 'the best overall theory of value must prove itself in its handling of hypothetical cases'. Indeed, according to Street, even if they are purely hypothetical, '[ICEs] haven't gotten anywhere near enough philosophical attention' (Ibid, p. 279)
} 
oddity of suggesting that you have no reason to order either option. It is unclear how an appreciation of the full extent of your confused and incoherent state of mind might incline us to accept that you have no reason to order either option for lunch - even though you judge that you ought to have sometbing for lunch, and even though you recognize that both options are nice, filling, inexpensive, etc. Unlike ICEs, you are (deeply) confused; you therefore require guidance as to how to resolve your situation, not acknowledgment that there is no normative fault in it. Such guidance might involve pointing out your conceptual or logical blunders. But if you are ideally incoherent, then presumably this would be of no use. And in that case, 'go for it' (i.e., have nothing for lunch) is hardly a reasonable thing to say to you. A much more natural reaction would be to try to explain how silly it is for you not to make a choice. (To be sure, your interlocutor's attempts may be doomed to fail, and then she may utter 'go for it' as a way of expressing her exasperation with you; but that is hardly the same thing as acknowledging the reasonableness of your position.)

All in all, then, it appears the constructivist can neither solve nor dissolve the problem of normative indeterminacy.22

\footnotetext{
22 Many thanks to Alex Gregory, Jonathan Way, and an anonymous reviewer for their detailed and extremely helpful written comments on previous drafts. I'm grateful also to an audience at the 2015 meeting of the European Normativity Network for discussion of material from this paper. The research was supported by the Israel Science Foundation (grant no. 1120/17).
} 